\title{
Cause-Effect Modelling of the Risk Analysis in Objects Development: An Application to Civil Structures
}

\author{
Luis-Emilio VELÁSQUEZ-RESTREPO a , Olga Eugenia URREGO- GIRALDO ${ }^{\text {a,b }}$ \\ and Germán URREGO-GIRALDO ${ }^{\text {a,1 }}$ \\ ${ }^{\mathrm{a}}$ Universidad de Antioquia \\ ${ }^{b}$ AREA Ingenieros Consultores S.A.S
}

\begin{abstract}
Cause-effect modelling, product-based analysis, and linguistic-based knowledge representation are concepts widely used in different engineering branches and offer ample ways for transdisciplinary engineering developments. An engineering solution consists of a tangible or intangible object able to satisfy specific requirements. The development of engineering projects faces many unknown, unpreventable, or uncontrollable phenomena. Risk analysis becomes an important item for project management. The identification of risks in the development of a solution is in general discretional, using particular models adapted to each specific project. On the contrary, we aim to a general and comprehensive risks analysis model, which is a non-common approach, based on products or results, for the identification of functionalities and defect causes of an object in a generic way. This article presents, in a product-based orientation, the definition of generic functionalities and generic causes categories of damage of an object. These main causes categories head the cause-effect model and constitute the set of adopted risk categories, which integrate the risk analysis model applicable to the development of tangible or intangible engineering solutions. The ex-post risks analysis of the collapse of a pre-stressed stayed bridge tower illustrates the use of the proposed risk analysis model.
\end{abstract}

Keywords. Object Functionalities, Cause-Effect Model, Risks Analysis, Knowledge Linguistic Model, Transdisciplinary Engineering, Civil Structures Risks

\section{Introduction}

In the development of engineering projects, as in general in human, social or natural activities there are many unknown, unpreventable, or uncontrollable phenomena, which bring incertitude to the previewed results. In this sense, risk analysis becomes an important item for the project management, aiming at successful project development, as it supported on the Project Experience Risk Information Library (PERIL) database, in [1], [2]. Risks in construction projects are treated in [3]. Risk analysis modelling in product innovation chain is the subject in [4]. Risk is the probability of having an adverse consequence, from the occurrence of an event. Many levels of risk may be considered in the activities and processes of a project, enclosed in the vulnerability concept, which constitutes a measure of propensity to have an adverse consequence. Risk and vulnerability are concepts defined initially in environmental sciences, among others in [5] and [6], but they are compulsory in engineering projects, in order to consider internal and external events affecting the activities and processes. Engineering has contributed to the development of risk models and their application in projects in different fields, as is described in [2], [4]. Risk models and methods of engineering support risk analysis in 
projects of diverse disciplines applying specific methods of theses, in a CrossDisciplinary environment.

A goal of our research team searches to extend the concepts of Requirements Engineering to other knowledge fields using also in this propose the methods of those knowledge fields, applying in this way, concepts of Transdisciplinary Engineering. These engineering concepts are treated, among others, in [7]. Research in this field is considered in sources [8][9]. In source [10] the focus is on sustainability in transdisciplinary engineering projects involving society and the social the natural environment. [11] Incorporates the trans disciplinarity in engineering megaprojects of urban development. Diverse forms of disciplinarity in engineering interventions and the extension of Transdisciplinary Engineering to processes of social sciences are introduced in [12]. Deeping in this concept we define, according to Context and Domain concepts introduced in sourcce [13], basic elements of a linguistic approach that involves the expression of action, activity, process and mega process in the frame of a linguistic template considering a verb and seven parameters related to semantic functions of the verb. This model is based on case grammar proposed by Fillmore in [14], and complemented by Foronda in [15], [16]. A verb may express in causative or descriptive way an action, activity, processes, or a level of mega process, in source [13]. Based on these elements, we are working on the development of a process grammar applicable in computational linguistics.

The identification of risks in the development of a solution is in general discretional and undefined, without an exhaustive way to understand and follow this search. Diversity of aspects related to an object difficult to find generic, defined, and exhaustive productbased approaches for risk analysis. All objects, means, methods and circumstances included in the development processes of a solution may be expressed by agents' interventions (actions and interactions) represented by the referred template integrated by a verb and seven parameters. Taking profit of this semantic richesse, we examine the verb and its semantic function in the agents' interventions template for creating a framework of generic functionalities and a framework of generic causes of object damage. This last framework constitutes a set of risks categories, which guides a strict identification of risks classified according to these categories.

The materialization of a risk becomes a problem. Events appearing in the interior of a process may bring adverse consequences and derivative problems affecting substantial elements of processes in the development of engineering projects. Events emerge as the origin of an effect on an object and a source of causes of this effect, which may be discovered in the proposed set of generic causes. Considering causes as problems, specific causes of these are identified, which are, in turn, treated as problems, for which more detailed causes may be found, and so on. Ishikawa condensed this type of reasoning in the denominated Cause-Effect Diagram, as it appears in [17], [18], [19].

The Cause-Effect Diagram is a good means in order to analyse the possible cause of fails of a product or a service. Our solution offers a frame of sixteen main causes, obtained from the generic functionalities of an object. The construction of the framework of generic functionalities takes into account the possible roles assumed by an object during his life and all aspects described in the linguistic template integrated by a verb and seven parameters or semantic functions of the verb. Main and specific causes were then validated with concepts represented in a Goals and Characteristics Model, a powerful domain model used for the development of a product line of civil engineering structures, which is treated in source [20]. The proposed framework of causes guided the collapse analysis of a support tower of a suspended bridge, in its construction period. 
This article includes in Section 1, after Introduction, elements for the definition of the framework of main causes. Cause-Effect Model for risks analysis is the subject of Section 2. Section 3 contains the application of risks analysis for the collapse of a support tower of a bridge. Section 4 describes the Conclusion and Future Work. The last Section presents the References.

\section{Elements for the Definition of the Main Causes Framework}

Problems related to an object acting as an agent appear in its interventions or in interventions of other agents using this object in some way. An agent is responsible for actions or interactions. An agent's intervention is an action of an autonomous agent or an interaction with other agents. We represent an agent intervention, through a template, in Figure 1, integrated by a verb and seven parameters indicating semantic functions of the verb. The template incorporates a verb, a main agent, an interacting agent, an object, a verb indicating causative or descriptive facts on the object, Situation 1 and situation 2 denoting changes occurred in the object, caused by that expressed by the verb. The means and method used by the main agent complete the seven parameters. So expressed agent's intervention constitutes a knowledge unit, useful for expressing inputs, results, and objects evolutions, considering evolution, transformations, operations, evaluations and decisions.

\begin{tabular}{|c|c|c|c|c|c|c|c|}
\hline MAIN & VERB & OBJECT & SITUATION & SITUATION & MEANS & METHOD & $\begin{array}{c}\text { INTERACTING } \\
\text { AGENT }\end{array}$ \\
\hline
\end{tabular}

Figure 1. Agent's Intervention Template.

An agent's intervention enriches the knowledge incorporated in objects there included, expressed in capacities and functionalities of these objects. The knowledgebased object development considers the knowledge acquired by its intervening agents, the knowledge associated with materials, means, methods, uses, technical, technological and scientific resources, and internal and external conditions affecting its development. Useful related aspects treated in the literature are described below in this paragraph. The Knowledge-based problem solving, in physical product development is presented in [21]. Perceptual knowledge related to physical object is considered in source [22]. Application of Knowledge Based Risk Management in Buildings is the subject in source [23]. Risk analysis based on Conceptual Object-Based is found in source [24]. Source [25][26] explains the transference of explicit and tacit knowledge.

In our research, we explore another way, based on the identification and treatment of knowledge associated to functionalities of an object. Agent's interventions involve an object in its different roles occurring in all moments and circumstances in the life of this object. The life of an object is a permanent incorporation of knowledge expressed in its functionalities and capacities. This paper introduces, in an object-based approach, the Generic Categories of Object's Functionalities, Figure 2, column 1, raised from the possible roles played by the object in its life, inspired by semantic functions in the before proposed linguistic template. Other article presents an approach discovering at first the Knowledge-Based Object's Capacities centered on processes of object's lifecycle phases.

Failures or problems in the functioning of an object correspond to problems in the realization of its functionalities. In this way, we use the sixteen discovered generic categories of an object's functionalities, listed in Figure 2, column 1, for identifying the 
generic causes of an object's problem. We take these generic causes as risk categories, as appear in Figure 2, column 2. The high-level causes will be the main causes in the cause-effect model in the next section.

\begin{tabular}{|c|c|}
\hline Object's Generic Functionalities & Generic Causes of an Object' Problem (Risk Categories) \\
\hline $\begin{array}{l}\text { What a tangible or intangible object does with the } \\
\text { knowledge that it requires, takes, rejects, or receives, } \\
\text { determining or affecting its nature, functioning or evolution. }\end{array}$ & $\begin{array}{l}\text { C1-Insufficiency in what a tangible or intangible object does } \\
\text { with the knowledge that it requires, takes, rejects, or receives, } \\
\text { determining or affecting its nature, functioning or evolution. }\end{array}$ \\
\hline $\begin{array}{l}\text { What an object can do with it knows and according to its } \\
\text { nature (essential characteristics or proprieties, structure, } \\
\text { shape, components) and its environment. }\end{array}$ & $\begin{array}{l}\text { C2-Deficiency in what an object can do with it knows and } \\
\text { according to its nature (essential characteristics or proprieties, } \\
\text { structure, shape, components) and its environment. }\end{array}$ \\
\hline What an object does with that it knows and enhances. & $\begin{array}{l}\text { C3-Inadequacy in what an object does with that it knows and } \\
\text { enhances. }\end{array}$ \\
\hline $\begin{array}{l}\text { What an object does with that it knows and proposes (its } \\
\text { function). }\end{array}$ & $\begin{array}{l}\text { C4-Incapacity in what an object does with that it knows and } \\
\text { proposes (its function). }\end{array}$ \\
\hline $\begin{array}{l}\text { What an object does with that it knows and diversifies (as a } \\
\text { means. method, input, resource, component, or other } \\
\text { uses). }\end{array}$ & $\begin{array}{l}\text { C5-Insufficiency in what an object does with that it knows and } \\
\text { diversifies (as a means. method, input, resource, component, } \\
\text { or other uses). }\end{array}$ \\
\hline $\begin{array}{l}\text { What an object does with that it knows and reaches to learn } \\
\text { and adopts. }\end{array}$ & $\begin{array}{l}\text { C6-Deficiency in what an object does with that it knows and } \\
\text { reaches to learn and adopts. }\end{array}$ \\
\hline $\begin{array}{l}\text { What an object does with that it knows, when revised, } \\
\text { verified, validated, correct, and rectified. }\end{array}$ & $\begin{array}{l}\text { C7-Inadequacy in what an object does with that it knows, when } \\
\text { revised, verified, validated, correct, and rectified. }\end{array}$ \\
\hline $\begin{array}{l}\text { What a tangible or intangible, produced or derivate object } \\
\text { does with that it knows, keeps, enables, and offers } \\
\text { according to its nature, functioning, or evolution. }\end{array}$ & $\begin{array}{l}\text { C8-Incapacity in what a tangible or intangible, produced or } \\
\text { derivate object does with that it knows, keeps, enables, and } \\
\text { offers according to its nature, functioning, or evolution. }\end{array}$ \\
\hline $\begin{array}{l}\text { What an object does with that it knows, configurates, shows } \\
\text { and differentiates (as a means. method, input, resource, } \\
\text { component, or other uses). }\end{array}$ & $\begin{array}{l}\text { C9-Insufficiency in what an object does with that it knows, } \\
\text { configurates, shows and differentiates (as a means. method, } \\
\text { input, resource, component, or other uses). }\end{array}$ \\
\hline $\begin{array}{l}\text { What an object does with that it knows and reaches to } \\
\text { recognizes and delimits. }\end{array}$ & $\begin{array}{l}\text { C10-Deficiency in what an object does with that it knows and } \\
\text { reaches to recognizes and delimits. }\end{array}$ \\
\hline $\begin{array}{l}\text { What an object does with that it knows, when reconfigured, } \\
\text { recuperated, isolated and particularized. }\end{array}$ & $\begin{array}{l}\text { C11-Inadequacy in what an object does with that it knows, when } \\
\text { reconfigured, recuperated, isolated and particularized. }\end{array}$ \\
\hline $\begin{array}{l}\text { What a tangible or intangible, produced or derivate object } \\
\text { does with that it knows, influences, determines and } \\
\text { stablishes according to its nature, functioning, or evolution. }\end{array}$ & $\begin{array}{l}\text { C12-Incapacity in what a tangible or intangible, produced or } \\
\text { derivate object does with that it knows, influences, determines } \\
\text { and stablishes according to its nature, functioning, or evolution. }\end{array}$ \\
\hline $\begin{array}{l}\text { What an object does with that it knows, identifies, affronts } \\
\text { and discovers (as a means. method, input, resource, } \\
\text { component, or other uses). }\end{array}$ & $\begin{array}{l}\text { C13-Insufficiency what an object does with that it knows, } \\
\text { identifies, affronts and discovers (as a means. method, input, } \\
\text { resource, component, or other uses). }\end{array}$ \\
\hline $\begin{array}{l}\text { What an object does with that it knows and reaches to } \\
\text { aggregate, substitute, eliminate, repair adapt, strength, } \\
\text { review, conserve, adjust, provide, support, assay, modify, } \\
\text { correct, update and receive. }\end{array}$ & $\begin{array}{l}\text { C14-Deficiency in what an object does with that it knows and } \\
\text { reaches to aggregate, substitute, eliminate, repair adapt, } \\
\text { strength, review, conserve, adjust, provide, support, assay, } \\
\text { modify, correct, update and receive. }\end{array}$ \\
\hline $\begin{array}{l}\text { What an object, intervening as mean, object, method or } \\
\text { agent does together with other agents on other objects, } \\
\text { with that it knows, integrates, isolates, interferes, activates, } \\
\text { stops, and stimulates. }\end{array}$ & $\begin{array}{l}\text { C15-Inadequacy in what an object, intervening as mean, object, } \\
\text { method or agent does together with other agents on other } \\
\text { objects, with that it knows, integrates, isolates, interferes, } \\
\text { activates, stops, and stimulates. }\end{array}$ \\
\hline $\begin{array}{l}\text { What a tangible or intangible, produced or derivate object } \\
\text { does with that it knows, conserves, retakes, adopts, } \\
\text { ensures and protects as technical conditions and uses } \\
\text { according to its nature, uses, risks and challenges. }\end{array}$ & $\begin{array}{l}\text { C16-Incapacity in what a tangible or intangible, produced or } \\
\text { derivate object does with that it knows, conserves, retakes, } \\
\text { adopts, ensures and protects as technical conditions and uses } \\
\text { according to its nature, uses, risks and challenges. }\end{array}$ \\
\hline
\end{tabular}

Figure 2. Generic Functionalities, Capacities and Problem Generic Causes of an Object. 


\section{Construction of Cause-Effect Model for Risks Analysis}

An engineering solution may be a product or service, expressed by tangible or intangible objects. The existence of an object or a solution may be seen as a space of permanent assimilation of knowledge and experiences when the object is disposed to be intervened or it is effectively intervened as an object in its role as means, resource, or method in some process and when it is able to intervene or it intervenes as an agent in this or in other processes. An agent's intervention is an independent action or an interaction with other agents.

The causes of problems associated with an object appear when it exercises its functions. We proposed in Section 1, Figure 2, a framework of generic functionalities that an object may do. Functionalities are discovered from object' roles considered in the agent's intervention template, depicted in Figure 2 Levels of knowledge incorporated by the object support the object's capacities. Limitation of generic functionalities constitute a set of generic causes of damages on an object. Generic causes constitute risk categories, which we use as top causes in the cause-effect diagram, in Figure 3. The central effect of damaged object determined by generic causes is enunciated as "Loss of the essence and functions of an object", as it is described in the cause-effect model in Figure 3. The causes $\mathrm{C} 1$ to $\mathrm{C} 16$ show as head causes of the main effect in Figure 3 are listed in Figure 2 column 2 . In turn, causes as limitations of each functionality have particular causes corresponding to essential elements involved in it.

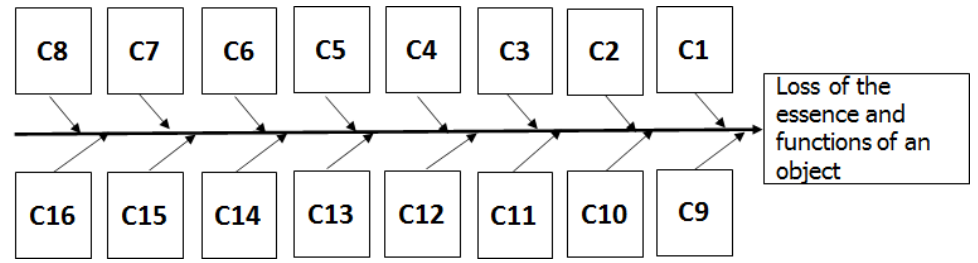

Figure 3. Cause-Effect Diagram.

Due to the extension of the whole set of causes, we show in the next paragraph, as an example, only the disaggregation of the first main cause, among 16 main causes, depicted in Figure 3.

C1- Insufficiency in what a tangible or intangible object does with the knowledge that it requires, takes, rejects, or receives, determining or affecting its nature, functioning or evolution.

- Deficiencies in previously built works

- Deficiencies in geology and soils

- Deficiencies in hydrological studies

- Inconsistency or incompleteness of technical standards used

- Inconvenient access conditions for people, equipment, materials

- Spaces and infrastructure inadequate for the construction of the works and for the operations on the site

- Adverse environmental conditions

- Deficiencies in the identification of the agents interested in the realization of the bridge and the actions and interactions that they must carry out in the processes of the phases of the bridge life cycle.

- Deficiencies in obtaining knowledge from studies, research and other sources, which must incorporate and use the bridge (as a solution). This knowledge is 
treated in the actions and interactions of the interested agents so that individually and collectively they satisfy their objectives in relation to the construction and use of the bridge.

- Deficiencies regarding the suitability, capacity, and experience of those who must intervene in the execution of the works

- Failures in the scheduling of activities

- Unreliable Suppliers and Supply Scheduling

- Non-availability of machinery, equipment and adequate technical resources

- Non-availability of adequate human resources

- Poor construction methods

- Deficiencies in the management model of the work on the site (planning, organization, direction, execution, review and control)

- Deficiencies in the construction plans

- Deficiencies in the supervision of construction

- Insufficiency of advice in Construction

Main and subordinate causes affect the bridge and its support towers as one of its constituent elements. Some causes may focus on a tower as our particular study object. In the next Section, we consider in the risk analysis an extract of nine categories of causes involved in the tower collapse of a bridge and an extract of their subordinated causes.

\section{Risks Analysis for the Collapse of a Support Tower of a Suspended Bridge}

The causes of an effect manifested in an object (a solution), in its construction period, appear in the interventions (actions, interactions) carried out on the conceptual and/or physical elements of this solution and in its interventions (actions and interactions) or of one of its constituents with other agents, including natural agents, in a predictable or unpredictable way. The main damage causes and their disaggregated causes constitute the proposed risk analysis model, which drives ex-post risks analysis for understanding the collapse cause of a tower of a pre-stressed stayed bridge, in the construction stage. In this stage, in addition to the previous interventions, appear the interventions (actions and interactions) of the object (solution) with multiple agents in different contexts, and the use of that object (solution), as a means, resource or as an input in the previous and ulterior processes.

Causes-Effect Analysis in the Collapse of a Stayed Bridge Tower (a solution constituent), in the period of construction of the bridge, starts with the identification of the main effect (problem): the collapse of a stayed bridge tower.

The tower directly or through its constituent elements and the relationships between them performs functionalities within the framework of generic functionalities introduced in Figure 2. Said functionalities reveal categories of causes for the problems that may arise in the tower during its construction and during the construction period of the other complementary objects of the bridge as a whole solution.

The framework of causes, introduced in Section 2, considers nine general causes and within each one, more specific causes are stated, and for each one of these, detailed causes appear. In some categories, this disaggregation of causes reaches only the second level in our example. The disaggregation of causes runs in general until the level that the available knowledge allows. The nine categories of causes correspond to the tower in its construction period. The other seven causes belong to the ulterior lifecycle phases after the construction phase. 
The present Section shows only 9 generic causes, (C1, C2, C3, C4, C5, C6, C7, C8, and $\mathrm{C} 15$ ), among 16 depicted in Figure 3, and their subcategories, needed to explaining, in an ex-post analysis, the collapse of the Chirajara bridge's tower, in Colombia, during the construction period. The first 8 main causes belong to the construction period, while the $\mathrm{C} 15$ corresponds to interaction with other agents, when the tower works during the whole bridge construction period. The depuration of those selected causes, using results of studies of interested parts and in situ observation, gave the nine specific causes highlighted bellow in bold italic type. The risk analysis model, originally conceived for anticipating solution for eventual future problems, supports the analysis and understanding the risks materialization in problems, and finally the explanation of causes of the tower collapse.

\subsection{Extract of Causes considered in tower collapse.}

C1-Insufficiency in what a tangible or intangible object does with the knowledge that it requires, takes, rejects, or receives, determining or affecting its nature, functioning or evolution.

\section{-Deficiencies in previously built works}

-Deficiencies in geology and soils

-Deficiencies in hydrological studies

-Inconsistency or incompleteness of technical standards used

-Deficiencies regarding the suitability, capacity, and experience of those who must intervene in the execution of the works

-Poor construction methods

-Deficiencies in the management model of the work on the site (planning, organization, direction, execution, review and control)

\section{-Deficiencies in the supervision of construction}

-Insufficiency of advice in Construction

C2-Deficiency in what an object can do with it knows and according to its nature (essential characteristics or properties, structure, shape, components) and its environment.

-Deficiencies in the conceptual structural model

C3-Inadequacy in what an object does with that it knows and enhances.

-Effect of the earthquake in the construction period

-Changes in geology, soils and hydrology after their studies, before and during the construction period

-Electric shock, winds and temperature changes in the construction period

-Manipulation of the built tower.

C4-Incapacity in what an object does with that it knows and proposes (its function).

-Deficiencies in the geometric properties (dimensions) of the tower and its components

-Deficiencies in materials

-Deficiencies in design methods

C5-Insufficiency in what an object does with that it knows and diversifies (as a means. method, input, resource, component, or other uses).

-Use of the tower or its components as support during construction

-Changes in the logical model of the structure caused in the construction

-Submit the tower or its components to unforeseen loads in terms of intensity or location during the construction period of the tower or of the bridge

C6-Deficiency in what an object does with that it knows and reaches to learn and adopts. 
-Changes in the mechanical properties of materials.

-Changes in the quantity and proportion of materials

-Changes in the internal structure of the tower. Changes in its components and in its organization.

C7-Inadequacy in what an object does with that it knows, when revised, verified, validated, correct, and rectified.

Causes that demand radical interventions:

-Insufficiency (Lack) of one or more elements of the tower.

-Loss of validity of one or more elements of the tower.

-Intromission or obstruction of one or more elements in the operation of the tower as a whole.

Causes that demand moderate interventions:

-Damage, deficiency, deterioration of one or more elements of the tower.

-Incapacity of one or more elements of the tower to fulfil some functions, assimilate changes in a context or behave within it.

-Saturation or limit requirement of the capacities of one or more elements of the tower.

The two types of causes detailed above in turn constitute problems that call for radical or moderate interventions (solutions).

C8-Incapacity in what a tangible or intangible, produced or derived object does with that it knows, keeps, enables, and offers according to its nature, functioning, or evolution.

-insufficiency of a constituent of the constructed tower

-Deficiency in objects, which behaviour affects the tower, during or after the construction time.

-Incorporation of cracks, alterations of the sections, modifications in the quality of the materials, and changes in the arrangement and treatment of the constituent elements, affecting the behaviour of the tower during its construction and in the construction period of other works of the project

C15-Inadequacy in what an object, intervening as mean, object, method or agent does together with other agents on other objects, with that it knows, integrates, isolates, interferes, activates, stops, and stimulates.

The object, in interactions with other objects, can act as a whole or as some of its parts.

Causes that demand radical interventions:

-Dispersion or divergence of constituent elements of the tower

-Disturbance or loss of connection of a constituent element of the tower due to the presence or actions of other elements or other external objects

Causes that demand moderate interventions:

-Suspension or extinction of functions of one or more constituent elements of the tower in relation to other elements

-Activity, movement or unwanted behaviour of one or more constituent elements of the tower affecting other elements

- Decrease or depletion of the ability of one or more constituent elements of the tower for acting in its relationship with other elements.

\subsection{Collapse Cause Analysis}

Last resume of causes contains only the possible causes more directly involved in collapse of a Chirajara bridge's tower, in Colombia. The depuration of those selected causes, using the results of studies of involved parts and in situ observation, gave the 
nine causes highlighted in grey colour. For the analysis of the selected causes and then depurate causes, the designers used worldwide recognized linear and nonlinear structural analysis methods, and the critical analysis of six studies contracted by interested parties in the bridge project development, as he exposes it in source [27]. Furthermore, designers considered independent structural analysis carried out by other designer, contracted by the bridge constructor, in source [28], and the evaluation of the tower behaviour realized by the prestigious consultant Cervenka, referred in soures [29], [30]. The study of causes considered in subsection 3.1, according to the referred critical analysis of six studies mentioned in the last paragraph, verified the certitude of the bridge design and highlighted the obligated occurrence of external extreme forces surpassing the preventable limits. The search of these forces considered the events perceived by workers at the moment of the tower failure, any earthquake registered at this moment, the way as the tower collapsed, the state of the structure and soil, before and after the collapse, the state of surrounding areas, particular cut surfaces of the tower constituents, and the settlement of $5 \mathrm{~cm}$ of the tower foundation. Cerveka simulated these conditions and probed the high magnitude of forces required for causing the collapse. The sudden settlement appears as a generator of an external force, determinant of the tower collapse. The results of studies executed by designers, consultants, and other firms guided an arbitration tribunal, convoked by the constructor and the concessionaire of the work, to exempt the design and the designer of responsibilities in the tower collapse.

\section{Conclusion and Future Work}

The product-based analysis allows discovering the generic capacities and functionalities of an object in terms of roles that it can assume. These generic abilities aid to overcome the high abstraction grade and subjectivity of a product-based model compared with a process-based one. Linguistic template based on grammar cases considers the roles of objects and supports the knowledge modelling. The incorporation of knowledge in an object (a solution) using linguistic structures supports the extension of engineering to any knowledge field in transdisciplinary approaches. Ongoing work aims at establishing a process grammar for supporting the computational linguistic in any knowledge field. Actions, activities, processes. mega processes and higher structures cantered on the verb, considered in our research, open other ways for the language research, useful in computational linguistic. In the development of tangible and intangible solutions, the product-based risk analysis model offers ample way for understanding the essence, qualities, and behaviour of objects. Cause-effect modelling shows the behaviour of objects during their life. Cause-effect constitutes an expressive option for determining risk categories and orienting the risk analysis of solution.

\section{References}

[1] C. Kendrick, Overcoming project risk: lessons from the PERIL database. PMI ${ }^{\circledR}$ Global Congress 2003, North America, Baltimore, Project Management Institute. Newtown Square, 2003.

[2] T. Kendrick, Identifying and Managing Project Risk, 2d Edition. Amacom, New York, 2009.

[3] P.X.W. Zou, G. Zhang, and J. Wang, Understanding the key risks in construction projects in China, International Journal of Project Management, 2007, Vol. 25, pp. 601-614.

[4] G. Urrego-Giraldo, G.L. Giraldo G. Process Modeling for Supporting Risk Analysis in Product Innovation Chain, 20th ISPE International Conference on Concurrent Engineering, Melbourne, 2013, IOS Press Amsterdam, pp 469-480.

[5] WCED. Our Common Future: The World Commission on Environment and Development. Bruntland Report, Oxford University Press, New York, 1987. 
[6] R. Chambers, Vulnerability, Coping and Policy, IDS Bulletin, Institute of Development Studies, University of Sussex, Brighton (England), April 1989, Vol. 20, No. 2. pp. 1-7.

[7] N. Wognum, C. Bil, F. Elgh, M. Peruzzini, J. Stjepandic and W. Verhagen, Transdisciplinary systems engineering Implications, challenges and research agenda, International Journal of Agile Systems and Management, 2019, Vol.12, No.1, pp. 58 - 89.

[8] G. Hirsch Hadorn, S. Biber-Klemm, W. Grossenbacher-Mansuy, H. Hoffmann-Riem, D. Joye, Ch. Pohl, U. Wiesmann, E. Zemp. The Emergence of Transdisciplinary as a Form of Research. In Handbook of Transdisciplinary Research. Ed. Springer Verlag, Bern, pgs. 19-42. 2008.

[9] N. Wognum, C. Bil, F. Elgh, M. Peruzzini, J. Stjepandić, W. Verhagen, Transdisciplinary engineering research challenges, Advances in Transdisciplinary Engineering, Vol. 7, 2018, pp. 753-762.

[10] G. Hirsch Hadorn, D. Bradley, C. Pohl, St. Rist, and U. Wiesmann. Implications of Transdisciplinarity for Sustainability Research, Ecological Economics, 2006, Vol. 60, Issue 1, pp. 119-128.

[11] G. del Cerro Santamaría, Towards Transdisciplinary Urbanism: Megaprojects, Power and the Urban Imagination. Transdisciplinary Journal of Engineering \& Science, 2018, Vol. 9, pp. 23-36.

[12] G. Urrego-Giraldo, G.L. Giraldo G., Engineering of Social Complex Realities, Advances in Transdisciplinary Engineering, Vol. 10, pp. 625-634.

[13] G. Urrego-Giraldo, ABC-Besoins: Une approche d'ingénierie de besoins fonctionnels et non-fonctionnels centrée sur les Agents, les Buts, et les Contextes. Ph.D. Thesis, Universidad Paris 1, Pantéon Sorbona, 2005.

[14] C. Fillmore, The case for case, The Ohio State University, 1967, http://files.eric.ed.gov/fulltext/ ED019631.pdf, Accessed: July, 32021.

[15] J.C. Foronda, Construcción de un modelo lingüístico para la representación del conocimiento contenido en textos escrito en lenguaje natural. Tesis de Maestría. Universidad de Antioquia, Medellín, Colombia, 2013.

[16] J.C. Foronda, G. Urrego, G. Giraldo, Identification of Knowledge Units Contained in Spanish Texts. In: G. Quiroz Herrera and P. Patino Garcia (eds.), LSP in Colombia: Advances and challenges, Peter Lang, Berlin, 2014, pp. 85-102.

[17] K. Ishikawa, Introduction to Quality Control, Springer, Dordrecht, 1990.

[18] M. Coccia, The Fishbone diagram to identify, systematize and analyze the sources of general-purpose technologies. Journal of Social and Administrative Sciences, 2017, Vol. 4, Issue 4, pp. 291-303.

[19] K. Ishii and B. Lee, Reverse fishbone diagram: a tool in aid of design for product retirement, Proceedings ASME design engineering technical conferences and computers in engineering conference, 96DETC/DFM-1272, 1996.

[20] G. Urrego-Giraldo, G.L. Giraldo G. and Olga-Eugenia Urrego, Introduction of a Goals and Characteristics Model for Implementing the Product Line Concepts: An Application in Civil Engineering, Advances in Transdisciplinary Engineering, Vol. 4, pp. 778-787.

[21] P. Burggräf, J. Wagner, Tim Weißer, Knowledge-based problem solving in physical product development. A methodological review, Expert Systems with Applications, 2020. Vol. 5, 100025.

[22] R.G. Meyers, Perceptual Knowledge and Physical Objects. In: The Likelihood of Knowledge. Philosophical Studies Series, Vol 38, Springer, Dordrecht, 1988, pp. 106-133.

[23] Y. Zou, S.W. Jones, and A. Kiviniemi, BIM and Knowledge Based Risk Management System: A Conceptual Model. Conference: CITA BIM Gathering 2015, November 12th -13th 2015, pp. 63-68.

[24] A.R. Short, Design of Autonomous Systems for Survivability through Conceptual Object-Based Risk Analysis, Colorado School of Mines. Thesis for the degree of Master of Science, 2011.

[25] C. Dhanaraj, M.A. Lyles, H.K. Steensma and L. Tihanyi, Managing tacit and explicit knowledge transfer in IJVs: the role of relational embeddedness and the impact on performance, Journal of International Business Studies, 2004, Vol. 35(5), pp. 428-442.

[26] N. Wognum, M. Wever, J. Stjepandić, Managing risks in knowledge exchange: Trade-offs and interdependencies, Advances in Transdisciplinary Engineering, 2016, Vol. 4, pp. 15-24.

[27] H. Urrego, How Powerful are the Models? Risk Intelligence of Infrastructures. IABSE Conference, Seoul, Korea, November 2020, S7-5.

[28] ICC. Structural Review Technical Report under construction conditions Chirajara Bridge (Spanish). July 16 2018. Medellín Colombia.

[29] N.N., Investigation of Chirajara Bridge Collapse Task 1: Pushdown analysis, Cervenka Consulting. 2018 .

[30] N.N., Investigation of Chirajara Bridge Collapse Task 3: Dynamic analysis, Cervenka Consulting. 26$10-2018$. 